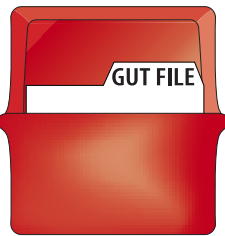

\title{
Transient ischaemic colitis following an aeroplane flight: two case reports and review of the literature
}

\section{INTRODUCTION}

Boley et al documented the first cases of reversible colonic injury resulting from ischaemia of the colon in $1963 .{ }^{1}$ At least 50 further cases have subsequently been reported in the literature with as yet no common aetiological factors elicited. ${ }^{2-10}$ This report documents two extensively investigated cases with no obvious precipitant except for a preceding aeroplane flight.

\section{CASE REPORT NO 1}

A 43 year old woman took a 10 hour flight to the USA. A few hours after arrival she developed vomiting, diarrhoea, and abdominal pain. She collapsed and was admitted to hospital where she had a further episode of diarrhoea with some fresh rectal bleeding. A diagnosis of gastroenteritis was made and she was discharged. Twenty four hours later she was admitted to another hospital with further rectal bleeding, abdominal pain, and a vasovagal episode. There were no abnormal physical findings. She underwent urgent colonoscopy which showed oedema, friability, and cobblestoning from the distal transverse colon to the descending colon (fig 1). Biopsies were taken from this area (fig 2) and showed a surface acute inflammatory cell exudate, mucosal haemorrhage, and gland dropout consistent with the effects of ischaemic damage. The rest of the large bowel was normal and ischaemic colitis was diagnosed. Her symptoms settled and she returned to the UK where she was referred as an outpatient.

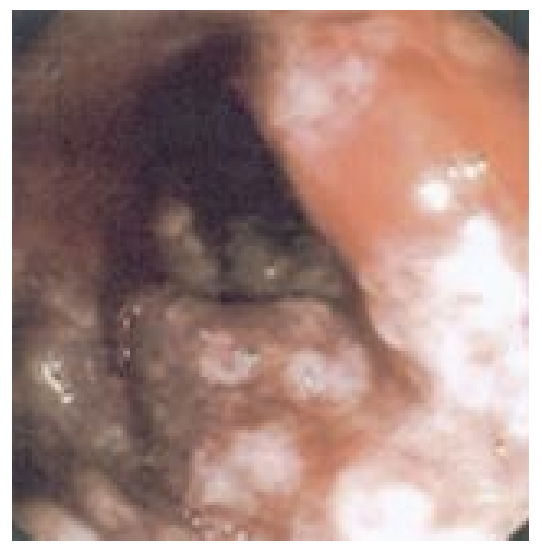

Figure 1 Endoscopic view showing oedema, friability, and cobblestoning.
There was no past history of coagulopathy or cardiac abnormalities and she did not smoke. She had not been taking any medication (including herbal remedies and oral contraceptives). Examination revealed no evidence of peripheral emboli or vasculitis. Heart sounds were normal and blood pressure was 115/70. Abdominal examination revealed mild right iliac fossa tenderness with no abdominal or peripheral bruits. Rigid sigmoidoscopy was normal as was her ECG. Initial investigations revealed: haemoglobin $13.3 \mathrm{~g} / \mathrm{dl}$, mean cell volume $90 \mathrm{fl}$, white cell count $7.3 \times 10^{9} / \mathrm{l}$, normal vitamin B12 and folate, erythrocyte sedimentation rate of 1 , and $C$ reactive protein not detected. Her electrolytes, albumin, alkaline phosphatase, alanine aminotransferase, and autoimmune profile were normal; hepatitis B surface antigen was not detected. A coagulation profile was normal together with an extended thrombophilia screen (lupusanticoagulant not detected, antithrombin III, factor V Leiden, protein C, and protein $\mathrm{S}$ normal). There is an association between plasma hyperhomocysteinaemia and cardiovascular disease $^{11}$ and therefore homocysteine levels and methionine levels were measured. These were also found to be normal. Flexible sigmoidoscopy was performed to $85 \mathrm{~cm}$ and demonstrated two residual linear scars in the sigmoid colon. The mucosa was otherwise unremarkable and biopsies from this area revealed mild non-specific inflammation. An echocardiogram demonstrated

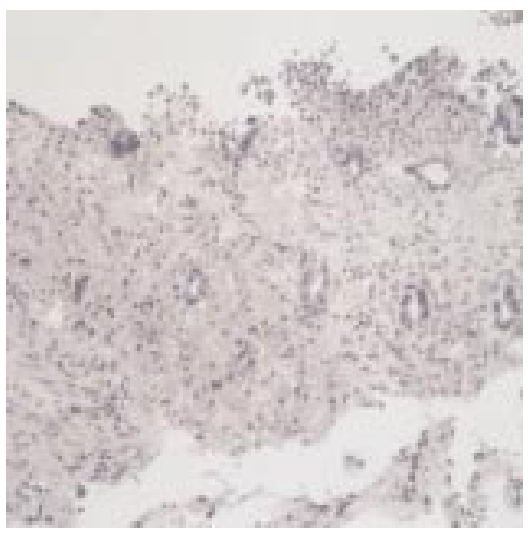

Figure 2 Biopsy showing a surface acute inflammatory cell exudate, mucosal haemorrhage, and gland dropout consistent with the effects of ischaemic damage. normal cardiac dimensions and trivial aortic regurgitation. An abdominal ultrasound scan detected no abnormalities and Doppler flow examination of the coeliac axis was normal. In view of the severity of the presenting illness, transfemoral abdominal aortography with selective angiography of the superior and inferior mesenteric arteries was performed. This did not demonstrate any primary visceral angiopathy or atheroma. The patient remained symptom free and was discharged five months after the initial episode.

\section{CASE REPORT NO 2}

A 38 year old man developed acute colicky abdominal pain with distension after a series of aeroplane flights within the preceding four weeks. During this period he had made a total of two transatlantic flights, four internal flights in the USA, and most recently within the last 24 hours a return flight in the UK lasting a total of two hours. He did not recall any abdominal symptoms after the long haul flights but passed blood and mucus per rectum followed by diarrhoea only a few hours after the most recent journey, and was admitted to hospital. There was no past medical history, and he was not taking any medication. He was a lifelong non-smoker. Examination was normal except for mild left iliac fossa tenderness. His abdominal pain rapidly resolved with cessation of the diarrhoea and bleeding. Rigid sigmoidoscopy at this time was normal. Stool culture was negative. The patient was discharged and an outpatient colonoscopy was arranged two weeks later. During this time he experienced two further episodes of self limiting diarrhoea. Colonoscopy revealed patchy erythema and mild oedema in a segmental position in the sigmoid colon. Histology revealed haemorrhage into the lamina propria and scattered haemosiderinladen macrophages. There was no excess of inflammatory cells in the lamina propria; crypt architecture and goblet cell populations were maintained. These features are consistent with mucosal haemorrhage secondary to ischaemia. A barium enema demonstrated mild sigmoid diverticular disease only. Haematological investigations revealed haemoglobin $15.6 \mathrm{~g} / \mathrm{dl}$, mean cell volume $9 \mathrm{l} \mathrm{fl}$, white cell count $6.4 \times 10^{9} / 1$, and platelets 
$214 \times 10^{9} /$. Erythrocyte sedimentation rate was 1 and $C$ reactive protein $3 \mathrm{mg} / \mathrm{l}$. Urea, electrolytes, albumin, bilirubin, and alkaline phosphatase were normal. Serum cryoglobulin, plasma fibrinogen, autoimmune profile, and cold agglutinins were negative. Serum immunoglobulins and protein electrophoresis were normal. Protein $\mathrm{C}$ and protein S, and antithrombin levels were normal.

\section{DISCUSSION}

The term "ischaemic colitis" was used by Marston et al in 1966 with three typical patterns of injury described: transient reversible ischaemia, ischaemic ulcers with stricturing, and gangrenous ischaemic colitis. ${ }^{12}$ The latter two patterns of ischaemic colitis occur predominantly in elderly and debilitated patients with significant comorbidity. ${ }^{13}$ However, the literature describes 50 cases of ischaemic colitis in otherwise "healthy" patients aged less than 50 years of age. ${ }^{2-9}$ In these individuals the condition is usually associated with complete recovery of the colon, in both structure and function, within one to two weeks. This essentially benign disorder is termed transient ischaemic colitis. ${ }^{13}$

Fifty cases of transient ischaemic colitis have been reported in patients aged 16-48 years over the last 30 years. ${ }^{2-9}$ Thirty seven $(74 \%)$ of the cases were women and $13(26 \%)$ were men. Typical symptoms reported are colicky abdominal pain, vomiting, and rectal bleeding. Patients often have minimal signs on clinical examination. A raised white cell count is often the only abnormality on blood tests. ${ }^{2}$ Barium enema may reveal characteristic "thumbprinting" with the condition most commonly affecting the splenic flexure and descending colon. Colonoscopy is the investigation of choice. ${ }^{13}$ Matsumoto et al described red oedematous mucosa in association with scarred longitudinal ulcers in all of their patients. ${ }^{5}$ Characteristic histological features include epithelial sloughing, oedematous and necrotic superficial mucosal layers with vascular congestion, mucin depletion, degeneration of normal crypt architecture, and a polymorphonuclear leucocyte mucosal infiltrate. ${ }^{2}$ In all 50 cases described the condition appeared to be self limiting with complete recovery within a few weeks. This clearly differs greatly from the outcome of ischaemic colitis reported in the older age group. ${ }^{8}{ }^{14}$ Four patients have been reported to have recurrence of symptoms, which again appeared self limiting. ${ }^{4}$

The patients with transient ischaemic colitis identified in the literature rarely had any underlying medical condition. Recorded predisposing factors include: previous abdominal surgery, ${ }^{5}$ history of thromboembolic disease, ${ }^{2}$ activated protein $\mathrm{C}$ resistance, ${ }^{10}$ protein $\mathrm{S}$ deficiency, hypovolaemic shock, ${ }^{8}$ vasculitis, ${ }^{13}$ drugs (for example, cocaine), ${ }^{13}$ diabetes, ${ }^{2}$ sickle cell disease, ${ }^{13}$ and long distance running. ${ }^{13}$ The most common association in young women is the use of the oral contraceptive pill which is reported to increase the relative risk of ischaemic colitis sixfold. ${ }^{4}$

Both patients in this report presented with typical symptoms of sudden onset colicky abdominal pain and bloody diarrhoea. Colonoscopic and histological findings were entirely in keeping with ischaemic colitis and both recoveries were uncomplicated. History, clinical examination, and extensive investigations excluded any of the recognised associations with ischaemic colitis.

The only potential risk factor we have elicited for transient ischaemic colitis in both of these patients is the aeroplane flight, and neither patient has been exposed to aeroplane travel since. The association between air travel and venous thrombosis is well recognised. However, only a few cases of flight related arterial thrombosis have been reported..$^{15-17}$ The mechanisms of arterial thrombosis remain unclear. Lower oxygen concentration, ${ }^{18}$ dehydration, and immobility ${ }^{19}$ may contribute. The effect of reduced air cabin pressure in animal models has been shown to increase the incidence of developing venous thrombosis. $^{20}$

J H Butcher, A J M Davis, A Page B Green, H A Shepherd

Gastroenterology, Histopathology, and Radiology Departments, Royal Hampshire County Hospital Winchester, Hampshire, UK

Correspondence to: Dr H A Shepherd, Gastroenterology Department, Royal Hampshire
County Hospital, Romsey Road, Winchester Hampshire SO22 5DG, UK; hugh@flexford.f9.co.uk

\section{REFERENCES}

1 Boley SJ, Lash J, Schwatz S, et al. Reversible vascular occlusion of the colon. Surg Gynec Obstet 1963;113:53-60.

2 Newell AM, Deckert JJ. Transient ischaemic colitis in young adults. Am Fam Physician 1997;56:1103-8.

3 Duffy TJ. Reversible ischaemic colitis in young adults. Br J Surg 1981;68:34-7.

4 Deana DG, Dean PJ. Reversible ischaemic colitis in young women. Association with oral contraceptive use. Am J Surg Pathol $1995 ; 19(4): 454-62$.

5 Matsumoto $T$, lida $M$, Kimura $Y$, et al. Clinical features in young adult patients with ischaemic colitis. J Gastroenterol Hepatol 1994;9:572-5.

6 Judge JS, Hoffman NE, Levitt MD. Transient ischaemic colitis in young adults. Aust N Z J Surg 1994;64:721-2.

7 Dudley HAF, Faris I. Ischaemic colitis without predisposing cause. BM 1971;3:637-8.

8 Sakai L, Keltner R, Kaminski D. Spontaneous and shock-associated ischaemic colitis. Am J Surg 1980;140:755-60.

9 Arnott IDR, Ghosh S, Ferguson A. The spectrum of ischaemic colitis. Eur J Gastroenterol Hepatol 1999;1 1:295-303.

10 Mann DE, Kessel ER, Mullins DL, et al. Ischaemic colitis and acquired resistance to activated protein $\mathrm{C}$ in a women using oral contraceptives. Am J Gastroenterol 1998;93:1960-2.

11 Verhoef P. Hyperhomocysteinaemia and risk of vascular disease in women. Semin Thromb Hemost 2000;26:325-34.

12 Marston A, Pheils MT, Thomas ML, et al Ischaemic colitis. Gut 1966;7:1-25.

13 Gandhi SK, Hanson MM, Vernava AM, et al Ischaemic colitis. Dis Colon Rectum 1996;39:88-100.

14 Longo WE, Ballantyne GH, Gusberg RJ. Ischaemic colitis: Patterns and prognosis. Dis Colon Rectum 1992;35:726-30

15 Teenan RP, Mckay AJ. Peripheral arterial thrombosis related to commercial airline flights: another manifestation of the economy class syndrome. Br J Clin Pract 1992;46:165-6.

16 Collins REC, Field S, Castleden WM. Thrombosis of leg arteries after prolonged travel. BM 1979;iv: 147-8.

17 Ashkan K, Nassim A, Dennis MS, et al. Acute arterial thrombosis after a long-hau flight. J R Soc Med 1998;91:324.

18 Aldrette JA, Aldrette LE. Oxygen concentrations in commercial aircraft flights. South Med J 1983;76:12-14.

19 Carruthers M, Arguelles AE, Mosouich A. Man in transit: biochemical and physiological changes during intercontinental flights. Lancet 1976;i:81

20 Hoffmann R, Schimmer RC, Largiader F. Surgery and environmental influence as risk-factors for the development of deep vein thrombosis in animal experiments. Thromb Haemost 1993:70:712-16. 